\title{
Current Status of Endoscopic Gallbladder Drainage
}

\author{
Joey Ho Yi Chan and Anthony Yuen Bun Teoh \\ Department of Surgery, The Chinese University of Hong Kong, Prince of Wales Hospital, Shatin, Hong Kong SAR China
}

The gold standard for treatment of acute cholecystitis is laparoscopic cholecystectomy. However, cholecystectomy is often not suitable for surgically unfit patients who are too frail due to various co-morbidities. As such, several less invasive endoscopic treatment modalities have been developed to control sepsis, either as a definitive treatment or as a temporizing modality until the patient is stable enough to undergo cholecystectomy at a later stage. Recent developments in endoscopic ultrasound-guided gallbladder drainage (EUSGBD) with EUS-specific stents having lumen-apposing properties have demonstrated potential as a definitive treatment modality. Furthermore, advanced gallbladder procedures can be performed using the stents as a portal. With similar effectiveness as percutaneous transhepatic cholecystostomy and lower rates of adverse events reported in some studies, EUS-GBD has opened exciting possibilities in becoming the next best alternative in treating acute cholecystitis in surgically unfit patients. The aim of this review article is to provide a summary of the various methods of GBD with particular focus on EUS-GBD and the many new prospects it allows. Clin Endosc 2018;51:150-155

Key Words: Endoscopic gallbladder drainage; Endoscopic ultrasound-guided gallbladder drainage; Percutaneous cholecystostomy; Cholecystitis, acute; Interventional endoscopic ultrasonography

\section{INTRODUCTION}

The gold standard for treating acute cholecystitis is laparoscopic cholecystectomy. ${ }^{1}$ However, cholecystectomy is often not suitable for surgically unfit patients with advanced age, multiple comorbidities, or malignancies. ${ }^{2}$ Percutaneous transhepatic cholecystostomy (PTC) is the standard method for drainage of the gallbladder in these patients. Recently, several endoscopic alternatives have been developed, and endoscopic ultrasound-guided gallbladder drainage (EUS-GBD) with the placement of lumen-apposing stents (LAMS) is gaining popularity over PTC. The aim of this review article is to give a summary on the current status in various methods of GBD

Received: August 8, 2017 Accepted: August 26, 2017

Correspondence: Anthony Yuen Bun Teoh

Division of Upper Gastrointestinal and Metabolic Surgery, Department of Surgery, The Chinese University of Hong Kong, Prince of Wales Hospital, 4F Clinical Science Building, Shatin, Hong Kong SAR China

Tel: +852-2632-2627, Fax: +852-2637-7974, E-mail: anthonyteoh@surgery.cuhk.edu.hk ORCID: https://orcid.org/0000-0002-1885-8035

(cc) This is an Open Access article distributed under the terms of the Creative Commons Attribution Non-Commercial License (http://creativecommons.org/ licenses/by-nc/3.0) which permits unrestricted non-commercial use, distribution, and reproduction in any medium, provided the original work is properly cited. with a particular focus on EUS-GBD and the many new prospects the technique allows.

\section{PERCUTANEOUS TRANSHEPATIC CHOLECYSTOSTOMY}

PTC has been considered the treatment of choice for GBD in high-risk patients who cannot undergo cholecystectomy. ${ }^{3,4}$ With a technical success rate of $98 \%$, a clinical success rate of $90 \%$, and a procedural adverse event rate of $3.7 \%$, it is also a highly effective method in relieving sepsis in acute cholecystitis in patients waiting to be reassessed for cholecystectomy. ${ }^{5}$ However, long-term adverse events and readmissions related to the external drainage catheter such as pneumothorax, biliary peritonitis, bleeding, and premature catheter removal or dislodgement have been reported in up to $12 \%$ of cases. ${ }^{6}$ Additionally, high rates of recurrent cholecystitis of up to $33 \%$ have been reported after catheter removal in patients who did not undergo cholecystectomy. ${ }^{7}$ Thus, endoscopic treatment has been developed with the aim of providing an improved means of GBD as well as obliterating the need for 
an external drain.

\section{ENDOSCOPIC GALLBLADDER DRAINAGE}

The gallbladder could be drained endoscopically using either the transpapillary or transmural approach. ${ }^{2}$ In the transpapillary approach, a duodenoscope is used to cannulate the cystic duct via the common bile duct in a manner similar to endoscopic retrograde cholangiopancreatoscopy (ERCP). In the transmural approach, a fistula is first created between the gallbladder and the duodenum or the stomach with the use of EUS. A plastic or metallic stent is then inserted for GBD into the gastroduodenal lumen.

\section{ENDOSCOPIC TRANSPAPILLARY GALLBLADDER DRAINAGE}

The development of endoscopic GBD for treating acute cholecystitis began in the 1990s with endoscopic transpapillary (ETP) naso-cholecystic drainage. ${ }^{8}$ The use of double pigtail stents to drain the gallbladder into the duodenum has also been described. ${ }^{2}$ ETP-GBD omits the need for an external drain and thus avoids any drain-related adverse events. It is associated with acceptable rates of technical (81\%-84\%) and clinical success (77\%-97\%), and adverse events (3\%) (Table 1). ${ }^{5,9-12}$ The clinical success and adverse events rates were also comparable to PTC (ETP-GBD vs. PTC $=69.8 \%$ vs. $62.5 \%$ and $8.2 \%$ vs. $4.8 \%$, respectively). ${ }^{13}$ To perform ETPGBD, proficient skills in cannulation of the cystic duct are required, which may not always be conceivable. ${ }^{2}$ Therefore, ETP-GBD may be preferred in treatment centers with a high level of expertise in ERCP in cases in which PTC is contraindicated, for example in severe coagulopathy, thrombocytopenia, or with an anatomically inaccessible position. However, similar to PTC, ETP-GBD only provides a temporary measure for controlling acute cholecystitis, with recurrent cholecystitis and biliary colic occurring in 10\% of patients after a median follow up of 17 months. ${ }^{14}$ In addition, migration of double pigtail stents after the procedure as well as additional ERCP-related complications such as bleeding, perforation, and post-ERCP pancreatitis have hindered the widespread acceptance of the technique. ${ }^{13,15}$

\section{ENDOSCOPIC ULTRASOUND-GUIDED TRANSMURAL GALLBLADDER DRAINAGE}

The development of transmural EUS-GBD has opened new avenues in controlling acute cholecystitis without the need for transpapillary access, which may sometimes be

Table 1. Outcomes of Endoscopic Transpapillary Gallbladder Drainage

\begin{tabular}{lccccc}
\hline Author & Year & Number of patients & Technical success (\%) & Clinical success (\%) & Adverse events (\%) \\
\hline Itoi et al. $^{9}$ & 2008 & 43 & 84 & 97 & - \\
Itoi et al. $^{5}$ & 2010 & 194 & 81 & 75 & 3.6 \\
Nakatsu et al. $^{10}$ & 1997 & 21 & 81 & 81 & - \\
Kjaer et al. $^{11}$ & 2007 & 34 & 70.6 & 87.5 & - \\
\hline
\end{tabular}
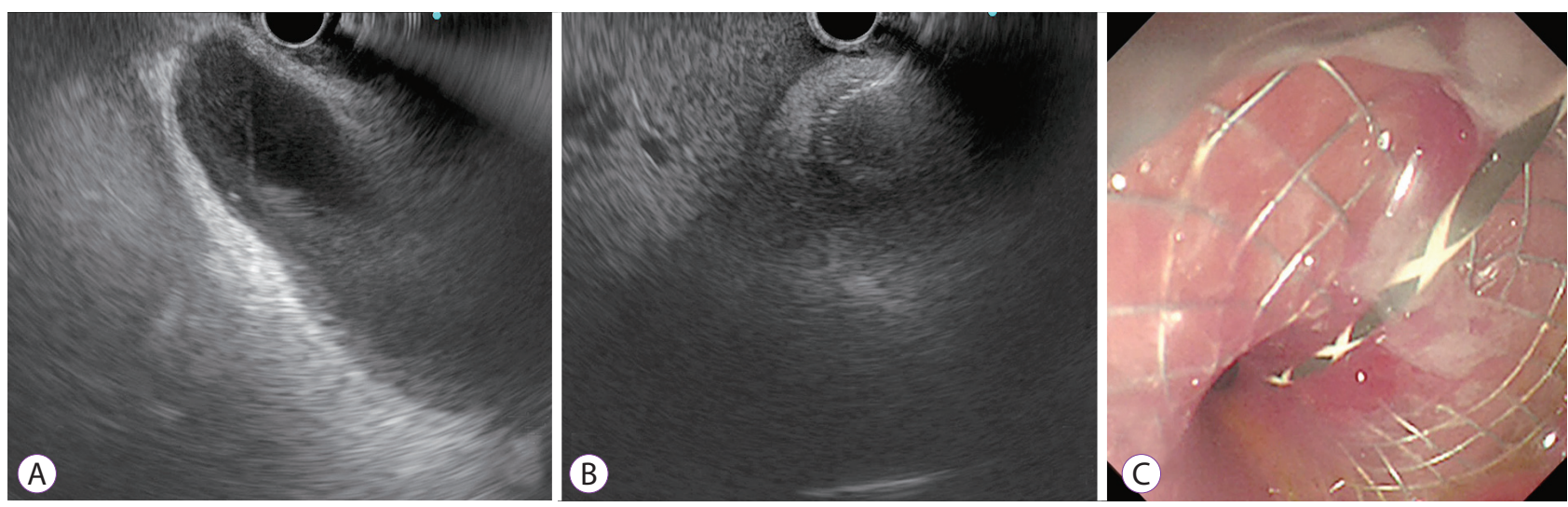

Fig. 1. Endoscopic ultrasound (EUS)-guided gallbladder drainage. (A) Acute cholecystitis with distended gallbladder noted on EUS. (B) Opening of the distal flange of the AXIOS stent (Boston Scientific, Marlborough, MA, USA). (C) Endoscopic view of the deployed stent in the duodenum. 
difficult to achieve. EUS guidance has allowed placement of transmural stents that allow drainage of the gallbladder via a transgastric or transduodenal approach (Fig. 1). The stent also acts as a portal to allow advanced gallbladder interventional procedures to be performed such as magnifying endoscopy, clearance of gallstones, or even polypectomy. ${ }^{16,17}$

Stent development has played a major role in the advancement of EUS-GBD. Previously, the lack of EUS-specific stents for transmural anastomosis hindered the technical and clinical success of EUS-GBD due to the inability to maintain tight organ apposition and prevent stent migration. The use of double pigtail catheters is associated with potential complications such as pneumoperitoneum, bile peritonitis, and stent migration. ${ }^{18}$ Whilst the use of fully covered biliary metallic stents (FCSEMS) for GBD may reduce the risk of bile leak, the stents will not maintain apposition between two non-adherent organs for the formation of a secure fistula. They are also too long for optimal positioning and can impinge onto the surrounding organs. Stent migration may also occur for FCSEMS. ${ }^{19}$

On the other hand, LAMS specific for EUS-guided deployment have been developed (Fig. 2). These stents are named LAMS as they generate enough lumen apposing force (LAF) to hold two non-adherent lumens together and prevent stent migration due to their lumen-apposing properties. ${ }^{20}$ In particular, a study has been conducted to objectively quantify lumen-apposing properties by measuring the LAF of three EUS-specific stents in four types of anastomosis. ${ }^{19}$ The EUS-specific stents evaluated were the AXIOS (Boston Scientific, Marlborough, MA, USA), NAGI (Taewoong, Gimpo, Korea), and SPAXUS (Taewoong) stents (Fig. 1). Each of these three types of LAMS is silicone- covered with anchoring flanges on either end that may be deployed using a deployment handle. The mean LAF produced by the AXIOS and SPAXUS stents in the cholecysto-gastric anastomosis were $2.64 \mathrm{~N}$ and $1.44 \mathrm{~N}$ respectively, which were significantly greater than $1.08 \mathrm{~N}$ produced by the NAGI $(p<0.001)$. However, the strength of the LAF that defines a LAMS is still uncertain. Thereafter, the development of a cautery-tipped stent delivery system that combines the functions of a cystotome, dilator, and stent delivery catheter system (Hot AXIOS; Xlumena Inc., Mountain view, CA, USA), allowed single-step LAMS deployment, reducing the need for switching between multiple instruments, which may result in an increased risk of adverse events. ${ }^{17}$ This new device has already been reported to be used successfully in drainage of the gallbladder and in peri-pancreatic fluid collections. ${ }^{17}$

\section{LONG-TERM EVALUATION OF ENDOSCOPIC ULTRASOUND-GUIDED GALLBLADDER DRAINAGE}

The potential of EUS-GBD, with placement of LAMS for the treatment of acute cholecystitis in patients who are unfit for surgery, is certainly promising. A multicenter prospective study has reported a high technical success rate of $90 \%$ and clinical success rate of $96 \%$ in 30 surgically unfit patients with acute cholecystitis. Serious adverse events were reported in 15 patients, where 4 out of 15 were stent or procedure-related and the other 11 were related to the underlying medical conditions of the patients. Two patients developed recurrent cholecystitis due to LAMS obstruction. ${ }^{21}$ In addition, technical failures were reported in $10 \%$ and technical difficulties

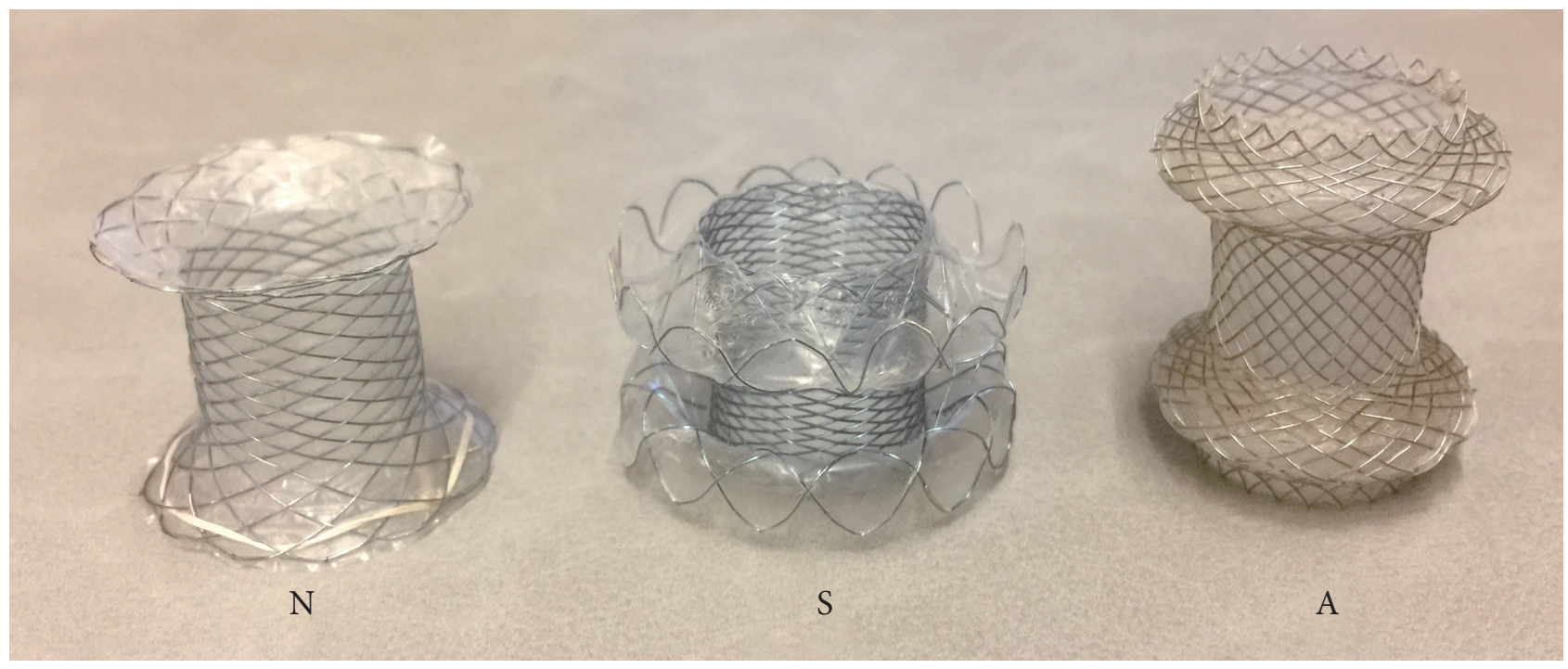

Fig. 2. Endoscopic ultrasound-specific stents. N, NAGI (Taewoong, Gimpo, Korea); S, SPAXUS (Taewoong); A, AXIOS (Boston Scientific, Marlborough, MA, USA). 
with LAMS deployment in 7\% of patients. Dollhopf et al. also reported a high technical (98.7\%) and clinical (95.9\%) success rate in EUS-GBD, with procedure-related adverse events occurring in 2 out of 75 patients and long-term adverse events reported in 5 out of 75 patients because of recurrent cholecystitis and stent migration. ${ }^{21}$ Thus, although high rates of technical and clinical success were achieved, data from these studies also suggest that the procedure may be associated with a steep learning curve when first adopted by an institution. ${ }^{21}$

On the other hand, whether the stents should be removed after acute cholecystitis is resolved remains uncertain. In theory, the stents could be removed once acute cholecystitis is resolved and all the gallstones have passed out of the gallbladder. However, the patients are often old and frail and they may not want to undergo a separate procedure for stent removal with permanent placement of the gallbladder stents. Multiple studies have reported the absence of adverse events arising from long-term stenting for up to three years with both self expandable metallic stents and LAMS.,22,23 Thus, permanent stenting may be a viable alternative in patients with limited life expectancy.

\section{COMPARISON BETWEEN ENDOSCOPIC ULTRASOUND-GUIDED GALLBLADDER DRAINAGE AND OTHER TREATMENT MODALITIES}

The use of EUS-GBD as an alternative to PTC presents a number of advantages. These include the avoidance of an external catheter, the potential to clear gallstones, and reduced post-procedural pain. While sharing similar success rates, EUS-GBD is associated with fewer adverse events and readmission rates associated with using an external drainage catheter. However, given the greater technical difficulty of the procedure, a steeper learning curve should be expected.

In recent studies, EUS-GBD and PTC were comparable in technical (95\%-98\% vs. 99\%-100\%) and clinical success rates (89.8\%-96\% vs. 89.8\%-94.9\%) (Table 2). ${ }^{5,24-27}$ Overall adverse events $(32.2 \%$ vs. $74.6 \%, p<0.001)$ and severe adverse events $(23.7 \%$ vs. $74.6 \%, p<0.001)$ were also significantly less in the EUS-GBD group as compared to the PTC group in 1 study. Adverse events arising from the PTC procedure included tube dislodgement (40\%), obstruction (29\%), peri-tubal leak, and wound infection (14\%). Rates of unplanned readmissions were also greater in the PTC than in the EUS-GBD group (6.8\% vs. $71.2 \%, p<0.001){ }^{26}$ This was due to issues arising from external drainage catheters in PTC, which accounted for $95.2 \%$ of readmissions. A reduced rate of recurrent acute cholecystitis in EUS-GBD has also been reported in comparison to PTC ( $0 \%$ vs. $6.8 \%, p=0.12$ ) as LAMS placement allows complete gallstone removal by baskets, mechanical, or laser lithotripsy. ${ }^{27}$ Hence, the outcomes of the above studies support EUS-GBD as the modality of choice in treatment of acute cholecystitis in patients who are unfit for surgery.

\section{DIAGNOSTIC AND THERAPEUTIC GALLBLADDER INTERVENTIONS AFTER ENDOSCOPIC ULTRASOUND-GUIDED GALLBLADDER DRAINAGE WITH LUMEN-APPOSING METAL STENTS}

The potential for advanced endoscopic assessment and interventions using LAMS as a portal to the gallbladder has been explored recently. ${ }^{27}$ Conventionally, the gallbladder is

Table 2. Comparison of Outcomes between Endoscopic Ultrasound-Guided Gallbladder Drainage and Percutaneous Transhepatic Cholecystostomy

\begin{tabular}{|c|c|c|c|c|c|c|c|c|c|c|}
\hline \multirow{2}{*}{ Author } & \multirow{2}{*}{ Year } & \multirow{2}{*}{$\begin{array}{l}\text { Number } \\
\text { of patients }\end{array}$} & \multicolumn{2}{|c|}{ Technical success (\%) } & \multicolumn{2}{|c|}{ Clinical success (\%) } & \multicolumn{2}{|c|}{ Adverse events (\%) } & \multicolumn{2}{|c|}{ Repeat interventions (\%) } \\
\hline & & & EUS-GBD & PTC & EUS-GBD & PTC & EUS-GBD & PTC & EUS-GBD & PTC \\
\hline Itoi et al. ${ }^{5}$ & 2010 & 321 & $\begin{array}{c}96 \\
(p=0.05)\end{array}$ & $\begin{array}{c}81 \\
(p=0.05)\end{array}$ & $\begin{array}{c}88 \\
(p=0.05)\end{array}$ & $\begin{array}{c}75 \\
(p=0.05)\end{array}$ & $\begin{array}{c}6.3 \\
(p=0.05)\end{array}$ & $\begin{array}{c}3.6 \\
(p=0.05)\end{array}$ & - & - \\
\hline Chan et al. ${ }^{27}$ & 2017 & 118 & $\begin{array}{c}96.6 \\
(p=0.15)\end{array}$ & $\begin{array}{c}100 \\
(p=0.15)\end{array}$ & $\begin{array}{c}89.8 \\
(p=0.30)\end{array}$ & $\begin{array}{c}94.9 \\
(p=0.30)\end{array}$ & $\begin{array}{c}32.2 \\
(p<0.001)\end{array}$ & $\begin{array}{c}74.6 \\
(p<0.001)\end{array}$ & - & - \\
\hline $\begin{array}{l}\text { Tyberg et } \\
\text { al. }^{25}\end{array}$ & 2018 & 155 & $\begin{array}{c}95 \\
(p=0.179)\end{array}$ & $\begin{array}{c}99 \\
(p=0.179)\end{array}$ & $\begin{array}{c}95 \\
(p=0.157)\end{array}$ & $\begin{array}{c}86 \\
(p=0.157)\end{array}$ & - & - & $\begin{array}{c}10 \\
(p=0.037)\end{array}$ & $\begin{array}{c}24 \\
(p=0.037)\end{array}$ \\
\hline Irani et al. ${ }^{24}$ & 2017 & 90 & $\begin{array}{c}98 \\
(p=0.88)\end{array}$ & $\begin{array}{c}100 \\
(p=0.88)\end{array}$ & $\begin{array}{c}96 \\
(p=0.20)\end{array}$ & $\begin{array}{c}91 \\
(p=0.20)\end{array}$ & $\begin{array}{c}11 \\
(p=0.065)\end{array}$ & $\begin{array}{c}32 \\
(p=0.065)\end{array}$ & $\begin{array}{c}12 \\
(p<0.05)\end{array}$ & $\begin{array}{c}124^{\text {a) }} \\
(p<0.05)\end{array}$ \\
\hline
\end{tabular}

EUS-GBD, endoscopic ultrasound-guided gallbladder drainage; PTC, percutaneous transhepatic cholecystostomy.

${ }^{a)}$ Most patients who underwent PTC received one repeat intervention after the initial procedure. 

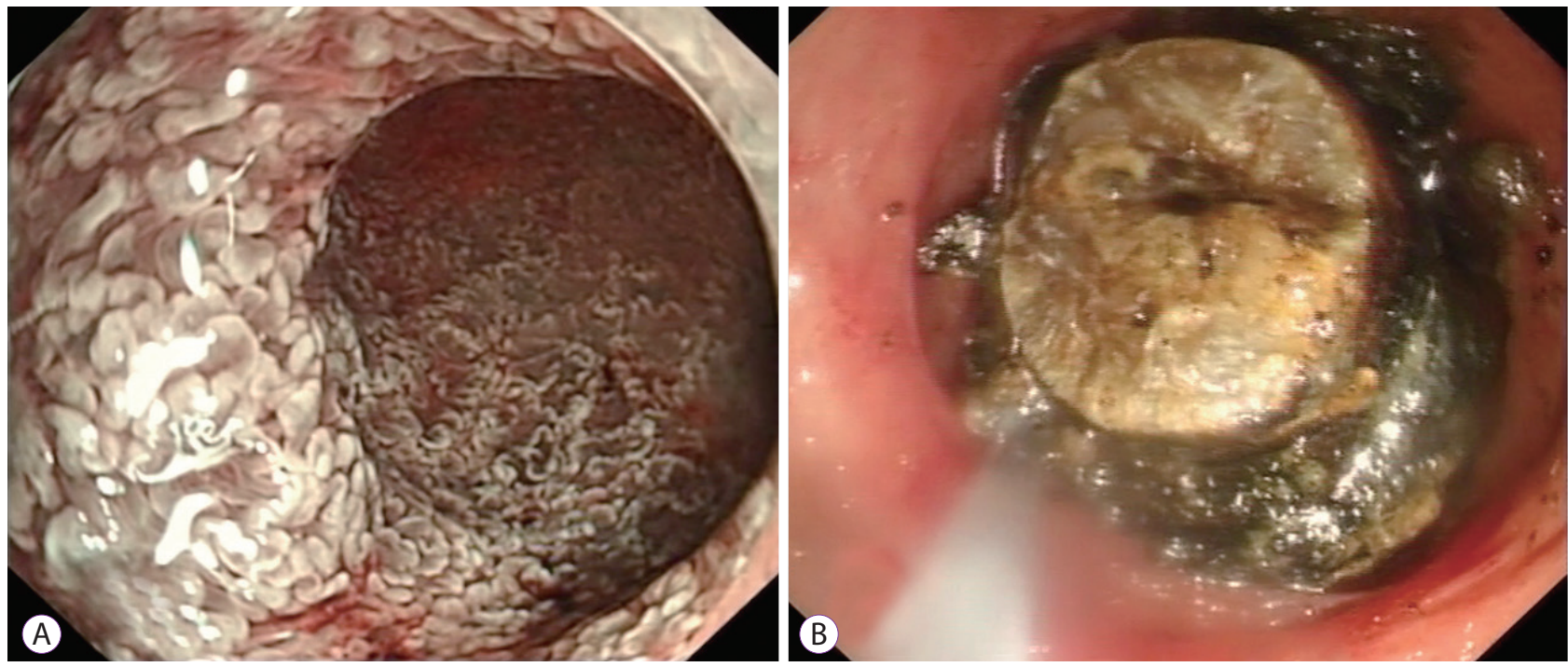

Fig. 3. Per-oral cholecystoscopy. (A) Narrow band imaging of the gallbladder mucosa. (B) Gallstone retrieval with a basket.

difficult to assess using the endoscope. However, the large diameter LAMS allow easy access of the endoscope into the gallbladder, providing new opportunities for endoscopic treatment of gallbladder diseases after EUS-GBD (Fig. 3). In a retrospective study, per-oral cholecystoscopy was performed routinely 1 to 3 months after LAMS placement. Spontaneous passage of gallstones was observed in $56 \%$ of the patients. In 3 patients, the remaining gallstones could also be removed with the use of irrigation, suction, basket (Olympus Medical, Tokyo, Japan), and a Roth net (US Endoscopy, Mentor, OH, USA), whilst another 3 patients with larger stones required the use of holmium laser lithotripsy (VersaPulse PowerSuite; UHS, Minneapolis, MN, USA). Overall, $88 \%$ of the patients achieved complete stone clearance.

In addition, a variety of image-enhanced modalities for mucosal evaluation of the gallbladder have been performed. Magnifying endoscopy was performed in 10 patients; it showed features suggestive of inflammation, which was subsequently confirmed to be acute-on-chronic or chronic inflammation on endoscopic biopsy. In one patient, magnifying endoscopy revealed a polypoid growth with irregular mucosal glands and a corkscrew microvasculature appearance highly suspicious of malignancy, which was not noted on computed tomography performed before EUS-GBD. ${ }^{28}$ Confocal laser endomicroscopy was also used to assess the lesion, which demonstrated epithelial structures with thick dark bands or dark clumps. ${ }^{28,29}$ Biopsy was taken and confirmed adenocarcinoma of the gallbladder. Furthermore, polyps discovered in 1 patient were removed by polypectomy with a snare (Olympus Medical) during the same cholecystoscopy session.

\section{CONCLUSIONS}

In conclusion, EUS-GBD with the placement of LAMS may replace PTC as the treatment of choice in surgically unfit patients with acute cholecystitis. The technique has opened new opportunities for managing gallbladder diseases endoscopically. Future studies will need to address the optimal duration of stenting, the need for gallstone removal after stenting, and whether EUS-GBD will make subsequent cholecystectomy more difficult. Studies are also required to further evaluate the role of EUS-GBD as a definitive management of acute cholecystitis.

\section{Conflicts of Interest}

The authors have no financial conflicts of interest.

\section{REFERENCES}

1. Teoh AY, Chong CN, Wong J, et al. Routine early laparoscopic cholecystectomy for acute cholecystitis after conclusion of a randomized controlled trial. Br J Surg 2007;94:1128-1132.

2. Yeung B, Teoh AY. Endoscopic management of gallbladder stones: can we eliminate cholecystectomy? Curr Gastroenterol Rep 2016;18:42.

3. Kortram K, de Vries Reilingh TS, Wiezer MJ, van Ramshorst B, Boerma D. Percutaneous drainage for acute calculous cholecystitis. Surg Endosc 2011;25:3642-3646.

4. Winbladh A, Gullstrand P, Svanvik J, Sandström P. Systematic review of cholecystostomy as a treatment option in acute cholecystitis. HPB (Oxford) 2009;11:183-193.

5. Itoi T, Coelho-Prabhu N, Baron TH. Endoscopic gallbladder drainage for management of acute cholecystitis. Gastrointest Endosc 2010;71:1038-1045.

6. McGahan JP, Lindfors KK. Percutaneous cholecystostomy: an alternative to surgical cholecystostomy for acute cholecystitis? Radiology 
1989;173:481-485.

7. Sugiyama M, Tokuhara M, Atomi Y. Is percutaneous cholecystostomy the optimal treatment for acute cholecystitis in the very elderly? World J Surg 1998;22:459-463.

8. Feretis CB, Manouras AJ, Apostolidis NS, Golematis BC. Endoscopic transpapillary drainage of gallbladder empyema. Gastrointest Endosc 1990;36:523-525.

9. Itoi T, Sofuni A, Itokawa F, et al. Endoscopic transpapillary gallbladder drainage in patients with acute cholecystitis in whom percutaneous transhepatic approach is contraindicated or anatomically impossible (with video). Gastrointest Endosc 2008;68:455-460.

10. Nakatsu T, Okada H, Saito K, et al. Endoscopic transpapillary gallbladder drainage (ETGBD) for the treatment of acute cholecystitis. J Hepatobiliary Pancreat Sci 1997;4:31-35.

11. Kjaer DW, Kruse A, Funch-Jensen P. Endoscopic gallbladder drainage of patients with acute cholecystitis. Endoscopy 2007;39:304-308.

12. Khan MA, Atiq O, Kubiliun N, et al. Efficacy and safety of endoscopic gallbladder drainage in acute cholecystitis: is it better than percutaneous gallbladder drainage? Gastrointest Endosc 2017;85:76-87.e3.

13. Itoi T, Takada T, Hwang TL, et al. Percutaneous and endoscopic gallbladder drainage for acute cholecystitis: international multicenter comparative study using propensity score-matched analysis. J Hepatobiliary Pancreat Sci 2017;24:362-368.

14. Mutignani M, Iacopini F, Perri V, et al. Endoscopic gallbladder drainage for acute cholecystitis: technical and clinical results. Endoscopy 2009;41:539-546.

15. Lee TH, Park DH, Lee SS, et al. Outcomes of endoscopic transpapillary gallbladder stenting for symptomatic gallbladder diseases: a multicenter prospective follow-up study. Endoscopy 2011;43:702-708.

16. Teoh AY, Binmoeller KF, Lau JY. Single-step EUS-guided puncture and delivery of a lumen-apposing stent for gallbladder drainage using a novel cautery-tipped stent delivery system. Gastrointest Endosc 2014;80:1171.

17. Swain CP, Mills TN. Anastomosis at flexible endoscopy: an experimental study of compression button gastrojejunostomy. Gastrointest Endosc 1991;37:628-631.

18. Teoh AY, Ng EK, Chan SM, et al. Ex vivo comparison of the lumen-apposing properties of EUS-specific stents (with video). Gastrointest Endosc 2016;84:62-68.

19. de la Serna-Higuera C, Pérez-Miranda M, Gil-Simón P, et al. EUS-guid- ed transenteric gallbladder drainage with a new fistula-forming, lumen-apposing metal stent. Gastrointest Endosc 2013;77:303-308.

20. Walter D, Teoh AY, Itoi T, et al. EUS-guided gall bladder drainage with a lumen-apposing metal stent: a prospective long-term evaluation. Gut 2016;65:6-8.

21. Dollhopf M, Larghi A, Will U, et al. EUS-guided gallbladder drainage in patients with acute cholecystitis and high surgical risk using an electrocautery-enhanced lumen-apposing metal stent device. Gastrointest Endosc 2017;86:636-643.

22. Choi JH, Lee SS, Choi JH, et al. Long-term outcomes after endoscopic ultrasonography-guided gallbladder drainage for acute cholecystitis. Endoscopy 2014;46:656-661.

23. Jang JW, Lee SS, Park DH, Seo DW, Lee SK, Kim MH. Feasibility and safety of EUS-guided transgastric/transduodenal gallbladder drainage with single-step placement of a modified covered self-expandable metal stent in patients unsuitable for cholecystectomy. Gastrointest Endosc 2011;74:176-181.

24. Irani S, Ngamruengphong S, Teoh A, et al. Similar efficacies of endoscopic ultrasound gallbladder drainage with a lumen-apposing metal stent versus percutaneous transhepatic gallbladder drainage for acute cholecystitis. Clin Gastroenterol Hepatol 2017;15:738-745.

25. Tyberg A, Saumoy M, Sequeiros EV, et al. EUS-guided versus percutaneous gallbladder drainage: isn't it time to convert? J Clin Gastroenterol 2018;52:79-84.

26. Teoh AYB, Serna C, Penas I, et al. Endoscopic ultrasound-guided gallbladder drainage reduces adverse events compared with percutaneous cholecystostomy in patients who are unfit for cholecystectomy. Endoscopy 2017;49:130-138.

27. Chan SM, Teoh AYB, Yip HC, Wong VWY, Chiu PWY, Ng EKW. Feasibility of per-oral cholecystoscopy and advanced gallbladder interventions after EUS-guided gallbladder stenting (with video). Gastrointest Endosc 2017;85:1225-1232.

28. Teoh AY, Chan AW, Chiu PW, Lau JY. In vivo appearances of gallbladder carcinoma under magnifying endoscopy and probe-based confocal laser endomicroscopy after endosonographic gallbladder drainage. Endoscopy 2014;46(Suppl 1) UCTN:E13-E14.

29. Nakai Y, Isayama H, Shinoura S, et al. Confocal laser endomicroscopy in gastrointestinal and pancreatobiliary diseases. Dig Endosc 2014;26 (Suppl 1):86-94. 